\title{
Correlation between Bone Scan Findings and CA 15- 3 in Patients with Carcinoma Breast
}

\author{
${ }^{1}$ Samira Sharmin, ${ }^{3}$ Jasmine Ara Haque, ${ }^{1}$ Md. Mahbub ur Rahman, ${ }^{1}$ Hosne Ara Rahman, ${ }^{1}$ Jamiul Hossain, \\ ${ }^{2}$ Md. Monir Uddin, ${ }^{1}$ Jesmine Ferdous, ${ }^{1}$ Farida Yasmin \\ ${ }^{1}$ Institute of Nuclear Medicine and Allied Sciences, Mitford, Dhaka \\ ${ }^{2}$ Radiology and Imaging, Bangabandhu Sheikh Mujib Medical University, Dhaka \\ ${ }^{3}$ National Institute of Nuclear Medicine and Allied Sciences, Dhaka
}

Correspondence Address : Dr. Samira Sharmin, Senior Medical Officer, Institute of Nuclear Medicine and Allied Sciences, Sir Salimullah Medical College campus, Mitford, Dhaka, E- mail: samira958@gmail.com

\begin{abstract}
Objectives: Breast carcinoma is the most life threatening malignant condition in women. This malignant disease commonly metastasizes to bone. Carbohydrate antigen (CA) $\mathbf{1 5 - 3}$ is a circulating human breast cancer associated antigen used as a tumor marker in the screening of breast cancer patients for metastasis. The objective of this study was to compare the levels of $\mathrm{CA} \mathbf{1 5 - 3}$ and bone scan findings in patients with breast cancer.

Patients and Methods: This cross sectional study was carried out at Institute of Nuclear Medicine and Allied sciences, Mitford, Dhaka, from January 2015 to December 2015. A total of 75 diagnosed breast cancer patients were enrolled in this study. All of them underwent bone scan. The tumor maker $\mathrm{CA}$ 15-3 was compared with bone scan findings. Pearson's correlation coefficient test was done to see the relationship between bone scan and CA 15-3.

Results: Mean age of the patients was $47.60 \pm 10.53$ years (range 25 to 65 years). About half (49\%) of the patients belong to the age group 50 years and above. Mean \pm SD of CA 15-3 was 84.06 \pm 104.60 $\mathrm{U} / \mathrm{ml}$ (range from 10.12 to $395.30 \mathrm{U} / \mathrm{ml}$ ). Out of 75 patients, 33 patients showed elevated CA $15-3$ level, among them $42 \%$ had negative bone scan with mean \pm SD CA $15-3$ level $60.98 \pm 9.95 \mathrm{U} / \mathrm{ml}$ (range 40.26-72.17 $\mathrm{U} / \mathrm{ml}$ ), $58 \%$ patients had positive bone scan with mean \pm SD CA 15-3 level $246.23 \pm 81.35 \mathrm{U} / \mathrm{ml}$ (range 110-395.30 $\mathrm{U} / \mathrm{ml}$ ). CA 15-3 was within normal limit (range 10.20-30.10 U/ml) in 42 patients. Among them $29 \%$ patients had negative bone scan and $\mathbf{7 1 \%}$ patients had positive bone scan. Pearson's correlation coefficient test showed positive relationship $(p=0.001, r=0.343)$ between CA 15-3 level and bone scan findings.

Conclusion: The result of the study showed positive relationship between the bone scan findings and CA 15-3 level of carcinoma breast patients.
\end{abstract}

Key words: Bone scan, Carcinoma Breast, CA 15-3 level.

\section{INTRODUCTION}

Bone metastasis is very common in breast cancer affecting approximately $70 \%$ of patient $(1,2)$. The detection of bone metastasis accurately reflects the prognosis and the early detection in the asymptomatic case may alert the clinician to the possible complications inherit in skeletal destruction (3, 4). Radioisotope bone scintigraphy is the most sensitive and the most common method for screening bony metastasis $(5,6)$. Carbohydrate antigen 15-3 (CA 15-3) is a tumor marker commonly used in the screening breast cancer patients for metastasis and monitoring treatment response $(7,8,9)$. The aim of this study was to find out the relation between bone metastasis and CA15-3.

\section{PATIENTS AND METHODS}

This analytical cross sectional study was carried out in the Institute of Nuclear Medicine and Allied Sciences, Mitford, Dhaka from January 2015 to December 2015. Total 75 histologically proven cases of primary carcinoma breast patient were enrolled in this study. The age range was 25 to 65 years and mean age was $47.60 \pm 10.53$ years. Bone scan was performed 2 hours after intravenous injection of $20 \mathrm{mCi}$ of $99 \mathrm{mTc}$ methylene diphosphonate (99mTc MDP) using Simen's dual Head Gamma Camera. Whole body anterior and posterior views were obtained for each patient. Patients medical records were checked for CA 15-3 levels. The biological reference interval of CA 15-3 was $<31.30 \mathrm{U} / \mathrm{ml}$. The collected data were compiled and analyzed using computer based software SPSS program, version 21. Bivariate analysis such as Pearson's correlation coefficient test and scatter diagram were performed to find out the association between two variables. In each analysis level of significance was 0.05 and $\mathrm{p}$ value $\leq 0.05$ was considered as statistically significant. 


\section{RESULTS}

Total 75 primary carcinoma patients with mean \pm SD age $47.60 \pm 10.53$ years (range, 25 to 65 years) were enrolled in this study. The bar diagram showed the distribution of the carcinoma breast patients at different age groups (Figure 1). About half (49\%) patients belonged to age group 50 years and above.

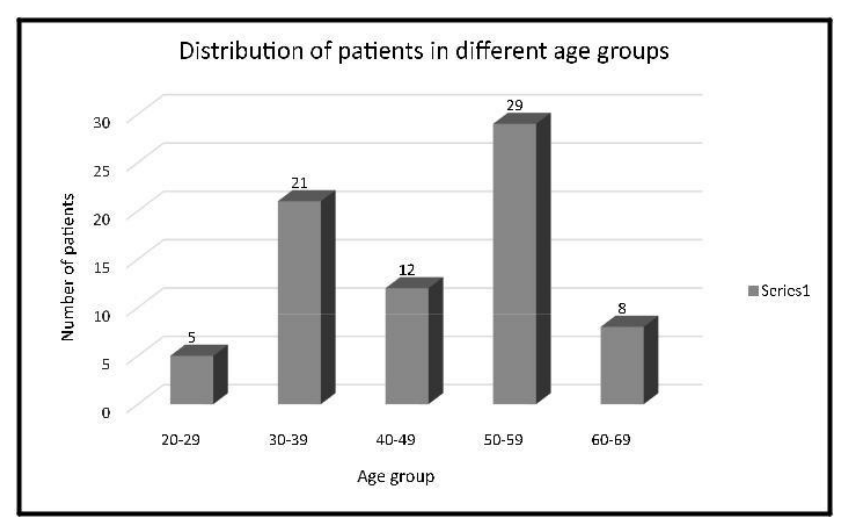

Figure 1: Bar diagram of distribution the carcinoma patients in different age groups.

In this study, the mean \pm SD of CA15.3 level was 84.06 $\pm 104.60 \mathrm{U} / \mathrm{ml}$, ranging from 10.12 to $395.30 \mathrm{U} / \mathrm{ml}$. Out of 75 patients, serum CA15-3 was within normal limit in $42(56 \%)$, elevated in 33(44\%) patients and bone scan was negative for metastasis in $44(58.7 \%)$ patients and positive for metastasis in 31(41.3\%) patients.

Among 42 patients with normal CA 15-3 level, bone scan was negative for metastasis in 30 patients (mean $\pm \mathrm{SD}$ of $\mathrm{CA} 15.3$ was $18.26 \pm 5.54 \mathrm{U} / \mathrm{ml}$ ) and positive for metastasis in 12 patients (mean \pm SD of CA 15.3 was $19.55 \pm 5.1$ ) (Table 1.).

Table 1: The distribution of patients with normal CA 15-3 level according to bone scan findings $(n=42)$.

\begin{tabular}{llll}
\hline Bone scan results & \multirow{2}{*}{$\mathrm{N}_{0.0}$ of Patients $(\%)$} & \multicolumn{2}{l}{ CA 15-3 value $\mathrm{U} / \mathrm{ml}$} \\
& & Mean \pm SD & Range \\
\hline Negative for metastasis & $30(71.4 \%)$ & $18.26 \pm 5.54$ & $10.20-30.10$ \\
Positive for metastasis & $12(28.6 \%)$ & $19.55 \pm 5.1$ & $12.45-28.26$ \\
\hline
\end{tabular}

Similarly out of 33 patients with elevated serum CA 15-3, bone scan was negative for metastasis in 14 patients (mean \pm SD of CA 15.3 was $60.98 \pm 9.95$ U.ml) and positive for metastasis in 19 patients (mean \pm SD of CA15.3 was $246.23 \pm 81.35 \mathrm{U} / \mathrm{ml}$ ) (Table 2.).
Table 2: Distribution of patients with elevated serum CA 15-3 level according to bone scan findings $(n=33)$.

\begin{tabular}{llll}
\hline Bone scan results & \multicolumn{1}{l}{$\mathbf{N}_{0}$ of patients $(\%)$} & CA 15-3 value U/ml & \\
& & Mean \pm SD & Range \\
\hline Negative for metastasis & $14(42.4 \%)$ & $60.98 \pm 9.95$ & $40.26-72.17$ \\
Positive for metastasis & $19(57.6 \%)$ & $246.23 \pm 81.35$ & $110-395.30$ \\
\hline
\end{tabular}

To see the relationship between CA 15-3 and bone scan, Pearson's correlation coefficient test was done and positive relation ( $\mathrm{p}=0.001, \mathrm{r}=0.343$ ) was observed between the two variables. The result was statistically significant $(\mathrm{p}<0.05)$ (Figure 2).

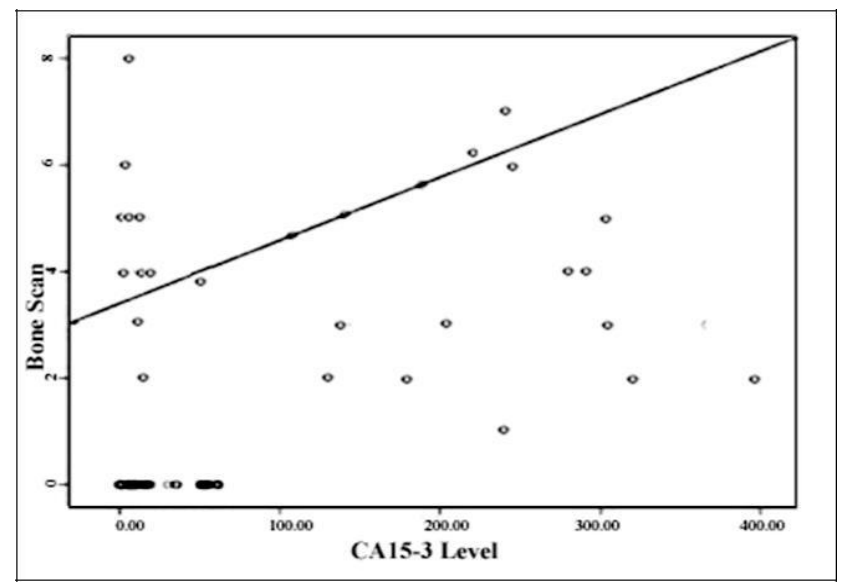

Figure 2: Pearson's correlation coefficient test shows the positive relationship between bone scan findings with CA 15-3 level

\section{DISCUSSION}

Bone metastasis is a common phenomenon in patients with breast cancer $(9,10)$. Older patients (50 years and above) are more affected than younger age group $(1,2,4)$. This might be due to the decreased net half life of collagen after menopause $(5,6,9)$. In this study about half (49\%) of the patients belonged to age group 50 years and above. Prognosis is strongly related with the extent of the disease. Bone scintigraphy is used in the management of breast carcinoma with high sensitivity and limited specificity $(11,12)$. Elevated CA 15-3 tumor markers sometimes provide evidence on undiagnosed metastasis in patients with breast cancer $(11,12,13)$.

In this study, out of 75 patients, $42(56 \%)$ had normal CA 15.3 level whereas 33(44\%) had raised CA 15-3 level, and 
$44(58 \%)$ patients had negative bone scan whereas $31(42 \%)$ had positive bone scan. Ghadge et al (2012) showed similar results. They showed that out of 70 patients, 55(78\%) had normal value of CA $15-3,15(22 \%)$ had raised level of CA 15-3 whereas $53(75 \%)$ had negative bone scans and $17(25 \%)$ had positive bone scans (1).

In another study done by Estrada-Sanchez et al. (2003), among 100 women with breast cancer showed that the mean value of CA15-3 for the patients without metastatic disease was $16.18 \mathrm{U} / \mathrm{ml}$ and for patients with bone metastasis was $164.02 \mathrm{U} / \mathrm{ml}$ (10). This present study is compatible with their findings showing that CA15-3 level for the patients without bony metastasis was $18.26 \pm 5.54 \mathrm{U} / \mathrm{ml}$ and patients with bony metastasis was $246 \pm 81.35 \mathrm{U} / \mathrm{ml}$.

In the current study, out of 75 patients 33(44\%) had elevated CA 15-3 level. Among them 14(18.67\%) had negative bone scan with CA 15-3 level $60.98 \pm 9.95$ $\mathrm{U} / \mathrm{ml}$ whereas $19(25.33 \%)$ had positive bone scan findings with CA 15-3 level $246.23 \pm 81.53 \mathrm{U} / \mathrm{ml}$. This finding was similar with a study conducted by Ghadge et al (2012). They showed that out of 70 patients 15 had elevated CA 15-3 level among them 6 had negative bone scan with CA 15-3 level $74.8 \pm 47.8$ whereas 9 patient had positive bone scan with CA 15-3 level $346.6 \pm 313.7 \mathrm{U} / \mathrm{ml}(1)$.

Gedik et al (2006) reported that small number of lesions was found in bone scans with relatively lower sensitivity of CA 15-3 level. They also showed that $62.5 \%$ patients had normal CA 15-3 level with metastatic scans (4). This finding is also similar with the current study showing $28.6 \%$ patients had positive bone scan with normal CA 15-3 level although Tomlinson et al (1995) reported no patients with normal CA 15-3 had bone metastasis (9).

In current study, Pearson's correlation coefficient test showed that there was positive $(\mathrm{r}=0.343, \mathrm{p}=0.001)$ relation between CA 15-3 level and bone metastasis in carcinoma breast patients. This finding was compatible with the study done by Begic et al (2006). They showed the weakly positive $(\mathrm{r}=0.096, \mathrm{p}=0.323)$ relationship with bone scan findings with CA15-3 level (3).

\section{CONCLUSION}

This study showed positive correlation between CA 15-3 level and Bone scan findings in patients with breast cancers. Therefore, CA 15-3 level tumor marker can be used as a preliminary tool for screening to select patients who needs radionuclide bone scan.

\section{REFERENCES}

1. Ghadge MS, Naik PP, Tiwari BP, Hedge RM, Matale TJ. A Comparative Study of Bone Scanfindings and serum levels of tumor Marker CA 15-3 in Patients with breast carcinoma. Indian J Clin Biochem 2012;27(1):97-99.

2. Yildiz M,Oral B, Bozkurt M, Cobaner A. Realtionship between bone scintigraphy and tumor markers in patients with breast cancer. Ann Nucl med. 2004;18(6): 15-20.

3. Begic A, Kucukalic-Selimoviv E, Obralic N, Duric O, Lacevic N, Skopljak A. Correlation between Bone Sctigraphy and Tumor Markers in Patients with Breast Carcinoma. Bosnian Journal of Basic Medical Sciences 2006;6(1):75-7.

4. Gedik G k, Kiratli PO, Tascioglu B, Aras T .Comparison of Bone Scintigraphy with Serum Tumor Markers of CA15-3 and Carcinoembryonic Antigen in Patients with Breast Carcinoma. Saudi Med J 2006;27(3):317-22.

5. Koizumi M, Yoshimoto M, Kasumi F,Ogata E. What do breast cancer patients benefit from static bone scintigraphy? Jpn J Clin Oncol 2001;31:263-69.

6. Yip CH, Paramosthy M. Value of routineTC-99m MDP bone scintigraphy in the detection of occult skeletal metastases in women with primary breast cancer. Breast 1999; 8(5): 267-9.

7. Aydiner A, Topuz E,Disci R, Yasasever V, Dincer M, Dincol K, Bilge N. Serum Tumor Markers for Detection of Bone Metastasis in Breast Cancer Patients .Acta Oncologica. 1994;33(2): 181-6.

8. Mohammadzadeh M, Alikahah H, Zareh AGA. Comparison of Bone Scan with Carbohydrate Antigen 15-3 for Evaluation of Bone Metastasis of Breast Cancer. Pakistan Journal of Biological Sciences 2010;13(4): 175-9.

9. Tomlinson IP, Whyman A, Barret JA, Kremer JK. Tumor markers CA15-3: possibly uses in the routine management of breast cancer. Eur. J. Cancer 1995;31:899-902.

10. Estrada-Sanchez DRG, Enriquez MM, Castaneda NV. Reliability of CA15-3 in the follow up of female patients with breast cancer and bone metastasis. Saudi Med J.2006;27:317-22

11. Agyei F MT, Darko E, Addi BW. The use of Carbohydrate Antigen (CA) 15-3 as a tumor marker in detecting breast cancer. Pak .J. Biol Sc 2008; 11:1945-48.

12. Buffaz PD, Gauchez AS, Caravel JP, Vuillez JP, Cura C, Agnius-Delord C, Fagret D. Can tumor marker assays be a guide in the prescription of bone scan for breast and lung cancers? Eur. J Nucl Med 1999;29:69-79.

13. Kitchen PRB, Andrews JT, Buckley JD, Russell IS, Lichtenstein M, McLean K,et al. An analysis of bone scintigraphy in early (operable) breast cancer .ANZJ Surg 2008;49(3):313-6. 